Article

\title{
Application of Spatial Time Domain Reflectometry for Investigating Moisture Content Dynamics in Unsaturated Loamy Sand for Gravitational Drainage
}

\author{
Guanxi Yan ${ }^{1, *(\mathbb{D}}$, Thierry Bore ${ }^{1}\left(\mathbb{D}, \mathrm{Zi} \mathrm{Li}^{1,2,3}\right.$, Stefan Schlaeger ${ }^{4}$, Alexander Scheuermann ${ }^{1}$ and Ling Li ${ }^{1,2,3}$ \\ 1 Geotechnical Engineering Centre, School of Civil Engineering, University of Queensland, St. Lucia, Brisbane, \\ QLD 4072, Australia; t.bore@uq.edu.au (T.B.); lizi@westlake.edu.cn (Z.L.); a.scheuermann@uq.edu.au (A.S.); \\ liling@westlake.edu.cn (L.L.) \\ 2 School of Engineering, Westlake University, Hangzhou 310024, China \\ 3 Institute of Advanced Technology, Westlake Institute for Advanced Study, Hangzhou 310024, China \\ 4 Science-Engineering-Measurement, Sceme.de GmbH, Horn-Bad Meinberg, \\ HRB 7181 Amtsgericht Lemgo, Germany; stefan.schlaeger@sceme.de \\ * Correspondence: g.yan@uq.edu.au
}

\section{check for} updates

Citation: Yan, G.; Bore, T.; Li, Z.; Schlaeger, S.; Scheuermann, A.; Li, L. Application of Spatial Time Domain Reflectometry for Investigating Moisture Content Dynamics in Unsaturated Loamy Sand for Gravitational Drainage. Appl. Sci. 2021, 11, 2994. https://doi.org/ 10.3390/app11072994

Academic Editor: Paulo José da Venda Oliveira

Received: 28 January 2021

Accepted: 23 March 2021

Published: 26 March 2021

Publisher's Note: MDPI stays neutral with regard to jurisdictional claims in published maps and institutional affiliations.

Copyright: (c) 2021 by the authors. Licensee MDPI, Basel, Switzerland. This article is an open access article distributed under the terms and conditions of the Creative Commons Attribution (CC BY) license (https:/ / creativecommons.org/licenses/by/ $4.0 /)$.

\begin{abstract}
The strength of unsaturated soil is defined by the soil water retention behavior and soil suction acting inside the soil matrix. In order to obtain the suction and moisture profile in the vadose zone, specific measuring techniques are needed. Time domain reflectometry (TDR) conventionally measures moisture at individual points only. Therefore, spatial time domain reflectometry (spatial TDR) was developed for characterizing the moisture content profile along the unsaturated soil strata. This paper introduces an experimental set-up used for measuring dynamic moisture profiles with high spatial and temporal resolution. The moisture measurement method is based on inverse modeling the telegraph equation with a capacitance model of soil/sensor environment using an optimization technique. With the addition of point-wise soil suction measurement using tensiometers, the soil water retention curve (SWRC) can be derived in the transient flow condition instead of the static or steady-state condition usually applied for conventional testing methodologies. The experiment was successfully set up and conducted with thorough validations to demonstrate the functionalities in terms of detecting dynamic moisture profiles, dynamic soil suction, and outflow seepage flux under transient flow condition. Furthermore, some TDR measurements are presented with a discussion referring to the inverse analysis of TDR traces for extracting the dielectric properties of soil. The detected static SWRC is finally compared to the static SWRC measured by the conventional method. The preliminary outcomes underpin the success of applying the spatial TDR technique and also demonstrate several advantages of this platform for investigating the unsaturated soil seepage issue under transient flow conditions.
\end{abstract}

Keywords: spatial TDR; moisture content; soil suction; SWRC; transient flow

\section{Introduction}

In nature, the vadose zone above the water table can be several meters high. In this zone, the moisture stored in the soil matrix does not fill the pores completely. This form of water is no longer in positive potential but negative, as it presents a capillary tensile interaction that binds the soil particles [1]. This binding interaction thus enhances the mechanical properties of unsaturated soil, resulting in less deformation [1,2] and higher shear strength $[3,4]$ compared to saturated soil, where water molecules encounter a compressive interaction [5]. Unsaturated soil mechanical behavior is, therefore, dependent on environmental conditions, which enhance or alleviate this binding effect, such as evapotranspiration and draining or flooding and intensive rainfall $[1,2,6]$. On the other hand, due to the air invasion into the soil matrix to form such a capillary water meniscus, the amount of effective hydraulic conductive channels is reduced as well and this degradation 
of geo-gas and groundwater flow conduits in unsaturated soil are highly concerning for the investigation of solute transport in the vadose zone [6]. For quantifying the contribution of capillary effects as water protentional in energy form and moisture content to the hydromechanical properties of unsaturated soil, the soil suction profile and soil moisture content profile need to be determined in order to characterize the soil water retention curve (SWRC), which is the core unsaturated soil constitutive relationship between the soil suction and moisture content (gravimetric/volumetric) [2].

The measurement of SWRC can be conducted either in the laboratory or in the field. In the laboratory, the standard axis translation technique (ATT) is often implemented [1]. Briefly, there is a one-dimensional representative elementary volume (REV) scaled soil specimen placed in a small fluid leakage-free chamber; through adding air pressure on top of the specimen, soil moisture can be expelled out of the soil matrix; the suction is the difference between applied air on top and water pressure at the bottom; the water moisture variation can be determined by measuring the mass of specimen or volume of water expelled out. Although ATT can be implemented in the laboratory due to the small set-up, this technique can only measure the SWRC under the static condition, for which there is no further moisture redistribution and capillary non-equilibrium. In the field, SWRC is usually given by separately measuring the suction profile using tensiometers and the moisture profile using in-situ sampling soil for the oven-drying method [7]. Compared to the ATT technique on a laboratory scale, this approach is more labor-expensive. In addition, sampling of soil disturbs the original configuration of the soil strata further, inducing moisture reconfiguration. This phenomenon is inevitable for in situ measurement and leads to potential falsification. Due to these limitations, there is always disagreement between the SWRC measured using ATT and in situ methods. Moreover, neither approach is able to measure the SWRC under the transient flow condition due to the requirement of equilibrium achievement and sampling procedure. Therefore, even for a homogeneous soil specimen, the conventional methods constrain the understanding of the spatial effect on soil suction determination [8,9], the temporal effect on moisture reconfiguration [10] and the dynamic effect in SWRC [11-13]. To overcome these limitations, there is a strong need for a laboratory experiment maintaining the homogeneity of a specimen in a full-scale soil profile without uncontrollable environmental conditions.

For measuring the SWRC under the transient flow condition, the spatially distributed moisture content needs to be measured with high temporal resolution. Some previous literature has implemented the soil column experiment using point-wise moisture sensors and tensiometers for logging the transient response of soil moisture and suction [12,14-16]. Nevertheless, these series of experiments only studied the dynamic effect of moisture and suction in a short sand column of less than $1 \mathrm{~m}$, and this did not cover the entire suction profile of sandy soil (approximately 0-2 m). Even though these dynamic SWRC studies allow the quantification of suction and moisture under the transient flow condition, they are not able to provide information on global suction/moisture profiles due to the smaller experimental scale. To collect information on both global suction and moisture profiles, the experimental set-up should be large enough to cover the sandy soil suction profile, and the moisture content profile should also be logged within a smaller time step as well. Therefore, the spatial time domain reflectometry (spatial TDR) developed by the Soil Moisture Group (SMG) at the University of Karlsruhe [17-19] was applied to the experimental studies of the non-uniqueness of the SWRC on a sand column experiment and levee model $[13,20]$. However, in these previous experimental investigations, a high air entry (HAE) ceramic disk, having higher hydraulic resistivity than sand, was placed under the specimen to build up the hydraulic connectivity between the hanging column reservoir and specimen. This might also result in alleviation of moisture seepage velocity and, additionally, reduce the significance of the dynamic response of suction and moisture redistribution.

With the aim of mitigating the shortcomings of these previous soil column tests, a novel experimental platform is developed in this study. In this experimental platform, the spatial TDR sensors are installed in sand columns to measure the TDR waveforms 
consistently during one-step gravitational drainage experiments. Taking advantage of this valuable moisture measuring technique, the moisture profile along a $240-\mathrm{cm}$ sand column can be calculated using an inverse modeling method developed by SMG [17-19]. With this powerful inverse technique, and by consistently logging TDR traces along the soil strata, a dynamic moisture profile with high spatial and temporal resolution can be achieved. With the addition of temporal logging of soil suction using a tensiometer along different elevations of the soil column, it is able to determine not only the point-wise SWRC at varied elevations but also the global suction/moisture profile under transient flow conditions. In this study, this novel laboratory-scale experimental set-up is presented. Furthermore, some preliminary outcomes of the gravitational drainage test are presented to demonstrate the capabilities of this experimental platform and eventually compared to the conventional hanging column method with discussions.

\section{Spatial Time Domain Reflectometry}

\subsection{Basic Principles of Time Domain Reflectometry}

Time domain reflectometry (TDR) has become an important monitoring technique for various civil engineering problems [21-24]; the main application is the monitoring of moisture content for porous media [25-28]. A TDR measurement system is composed of a pulse generator combined with an oscilloscope and a transmission line system (see Figure 1a). The transmission line includes a leading coaxial cable and a sensing waveguide, called the TDR probe, which is embedded in the medium for characterization. The characteristics (length and geometry) of the probe depend on the application. The classical geometry remains in the rod configuration. The pulse generator delivers an electromagnetic pulse along the transmission line, and the oscilloscope records returning reflection. Reflection will occur at any impedance discontinuities along the transmission line. In particular, the pulse will be reflected at the beginning and end of the TDR probes. The travel time analysis between these two reflections can be used to determine the flight time $\Delta t$ of the pulse to travel along the probe. This flight time is generally computed based on the dual tangent method [29], where the reflection arrival is located at the intersection of the two tangents to the TDR curve (see Figure $1 b$ ). Finally, the apparent permittivity $\varepsilon_{a p p}$ of the medium can be determined with the well-known relation:

$$
\varepsilon_{a p p}=\left(\frac{c_{0} \Delta_{t}}{2 L_{p}}\right)^{2}
$$

where $c_{0}$ is the speed of the light and $L_{p}$ is the length of the probe. Please note that for most porous media, the permittivity is complex and frequency-dependent (dispersion). The term apparent permittivity is used here because the time-domain method does not intend to compute the complete frequency-dependent complex permittivity.

In a second step, the apparent permittivity is linked to the parameter of interest-in most cases, water content, $\theta$. The most frequent method is to use the empirical equation. The classical example is the famous Topp equation [30]:

$$
\theta_{\text {Topp }}=-5.3 \times 10^{-2}+2.92 \times 10^{-2} \varepsilon_{a p p}-5.5 \times 10^{-4} \varepsilon_{a p p}{ }^{2}+4.3 \times 10^{-6} \varepsilon_{a p p}{ }^{3}
$$

The accuracy of such an empirical model highly depends on the nature of the soil related to density, the salinity of soil water, mineral composition, etc. For example, Topp's equation is not suitable for high swelling clay mineral [31]. An alternative to this solution is to derive a material-specific calibration functions [32].

Another approach relies on a physical model based on mixture equations $[33,34]$. Mixing models consider the soil as a medium that is composed of different phases. The 
relative permittivity of the mixture $\varepsilon_{m}$ is the result of the sum of the dielectric properties of each phase multiplied by its volume fraction:

$$
\varepsilon_{m}^{a}=\sum_{k=1}^{N} V_{k} \cdot \varepsilon_{r, k}^{a}
$$

where $N$ is the number of phases, $a$ is a structure parameter, $V_{k}$ is the volume fraction and $\varepsilon_{r, k}$ is the relative permittivity of the solid phase. The classical configuration for the mixture equation is the three-phase mixtures (air-solid-liquid) with a structure index equal to 0.5, called the Complex Reflective Index Model (CRIM) [35]. In this configuration, $\varepsilon_{m}$ can be expressed directly as a function of water content [36]. The main source of interest of such models is the versatility: they can take into account the temperature and frequency dependence of the single components. The main disadvantage of such a method is the lack of knowledge and understanding of the interaction between single components.

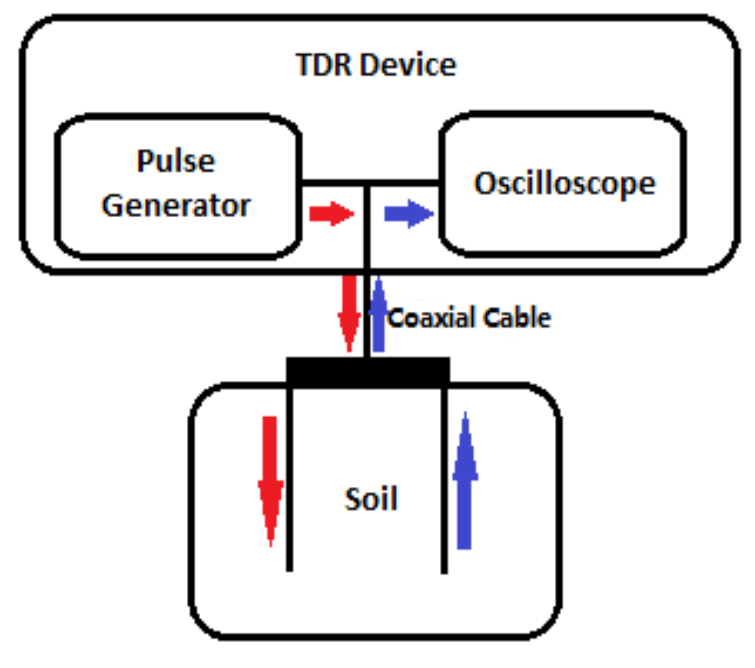

(a)

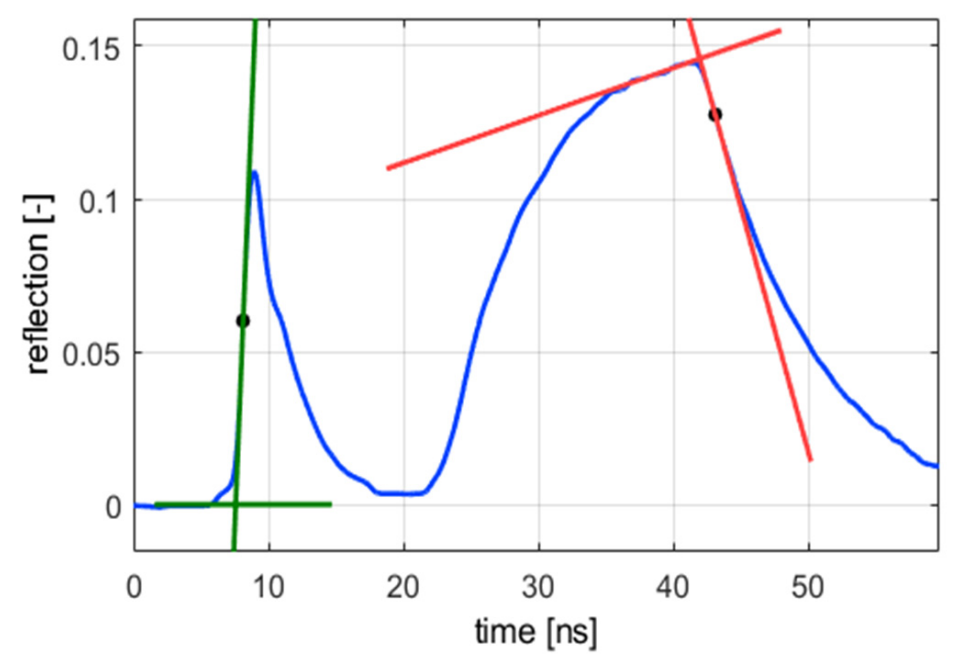

(b)

Figure 1. (a) Schematic description of Time Domain Reflectometry (TDR) device (pulse generator for sending a signal and oscilloscope for receiving) and TDR sensor plugged into a bulk of soil; (b) TDR waveform for saturated sand with the travel time determined by tangent method (reflection coefficient is dimensionless).

\subsection{Spatial Time Domain Reflectometry Sensor Development}

For the purpose of measuring natural porous media on a large scale, conventional TDR has its limitations, especially concerning the measurement of spatially distributed moisture, as probes are usually constructed as small three-pin or two-pin probes, which can only give a point measurement. Spatial TDR was developed by SMG at the Karlsruher Institute of Technology (KIT), Karlsruhe, Germany, to enable moisture profile measurements [17-19,37]. A flat ribbon cable consisting of three-line copper wire covered with polyethylene insulation is usually used for this purpose. An example of the spatial TDR sensor is given in Figure 2a. The corresponding conceptual model of the electrical circuit of a TDR transmission line and capacitance model are separately shown in Figure 2b,c. The electrical circuit of an infinitesimal section along the cable can be treated as the electrical circuit plotted in Figure $2 b$. The electrical design of the sensor was developed by Huebner, C. et al. [18].

For such a infinitesimal section, information on the surrounding soil and coating material properties can be extracted from the conductance $(G)$ and capacitance $(C)$ using inverse modeling of the telegraph equation [19,38-41]. For instance, one version developed by Schlaeger [5] is selected to conduct the inverse analysis in this study. Before inverse modeling, some assumptions and set-up conditions have to be achieved: 
1. The resistance is assumed to be constant at a value of zero for lower frequencies $\left(<10^{4} \mathrm{~Hz}\right)$, because, in practical cases, dielectric losses are much higher than resistance losses, with the exception of long sensors buried into a nearly lossless material such as snow [18];

2. The inductance is assumed to be constant $\left(L_{0}\right)$ for lower frequencies $\left(<10^{4} \mathrm{~Hz}\right)$, because only the external inductance remains at the highest frequency $\left(10^{6} \sim 10^{9} \mathrm{~Hz}\right)$, and a transition frequency around $100 \mathrm{kHz}$ ensures the insignificant influence of the inductance increase at a low-frequency range within the time window of TDR measurement [18];

3. The conductance and capacitance depend on the surrounding moist sandy soil and are assumed to be independent of frequency for lower frequencies $\left(<10^{5} \mathrm{~Hz}\right)$ [17];

4. The performance of the flat ribbon cable sensor is very sensitive to the installation in accordance with the 3-D electromagnetic modeling analysis [37] because the air-filled gap of $0.25 \mathrm{~mm}$ on both sides of the flat ribbon cable causes significant underestimation of moisture content, while a water-filled gap leads to overestimation $[17,36]$.

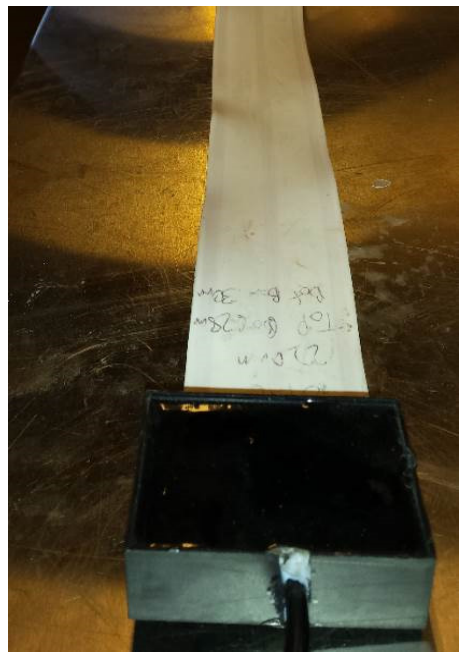

(a)

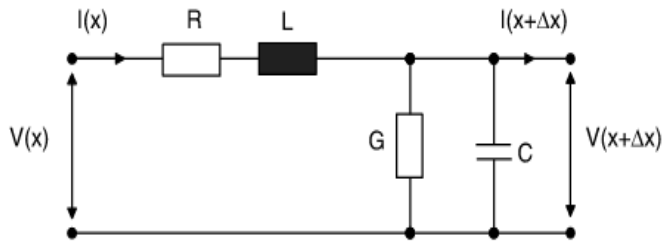

(b)

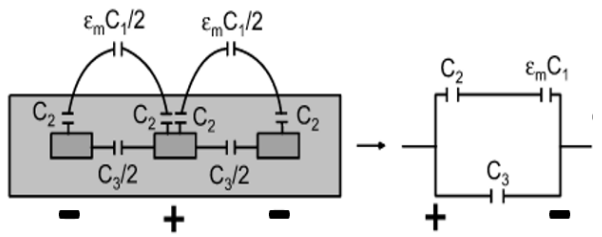

(c)

Figure 2. (a) Flat ribbon cable used for spatial TDR measurements; (b) equivalent circuit of an infinitesimal section of cable sensor [18]; (c) capacitance model of the flat ribbon cable [17].

\subsection{Spatial Time Domain Reflectometry Forward Modeling}

Based on the above assumptions and ideal sensor installation conditions, the inverse technique on two-way TDR tracing to extract $C$ and $G$ profiles can be executed. According to the electrical circuit simplified in Figure $3 a$, the forward modeling telegraph equation can predict the TDR trace along a flat ribbon cable. Therefore, the finite difference method is applied to numerically solve these equations with boundary conditions exactly matching the physical sensor design to predict the TDR trace [38,40-42]. To simplify the original telegraph equations for solving, Schlaeger transformed two first-order governing partial differential equations (PDE) into a single PDE in second-order as Equation (4):

$$
\left[L C(x) \frac{\partial^{2}}{\partial t^{2}}+L G(x) \frac{\partial}{\partial t}+\frac{\partial L / \partial x}{L} \cdot \frac{\partial}{\partial x}-\frac{\partial^{2}}{\partial x^{2}}\right] U_{i}(x, t)=0
$$


where $L$ is inductance, assumed to be constant because of the second assumption; $C$ and $G$ are, separately, capacitance and conductance in functions of cable length $x$ because of the third assumption; $U$ is the voltage predicted for plotting the TDR trace $(i=1,2$ represents first and second TDR tracing); the resistance $R$ is assumed to be zero because of the first assumption depicted in Figure 3a. The appropriate initial and boundary conditions for solving Equation (4) to replicate the TDR trace have been discussed in Schlaeger's forward modeling work in detail [42]. Due to the requirement of two unknown input state variables ( $C$ and $G$ profiles), two-way TDR tracing has to be implemented using a TDR device combined with a multiplexer, as described in Figure $3 b[18,19]$. The TDR device should send voltage steps through one channel of the multiplexer and then should be immediately switched to the second channel to collect the TDR waveform from the other terminal. Thus, through solving Equation (4) twice to match the two TDR waveforms collected from both terminals, the two unknown input profiles can be determined. Moreover, the forward modeling domain is constrained within two sensor terminals corresponding to two inflection points along a single TDR waveform [17].

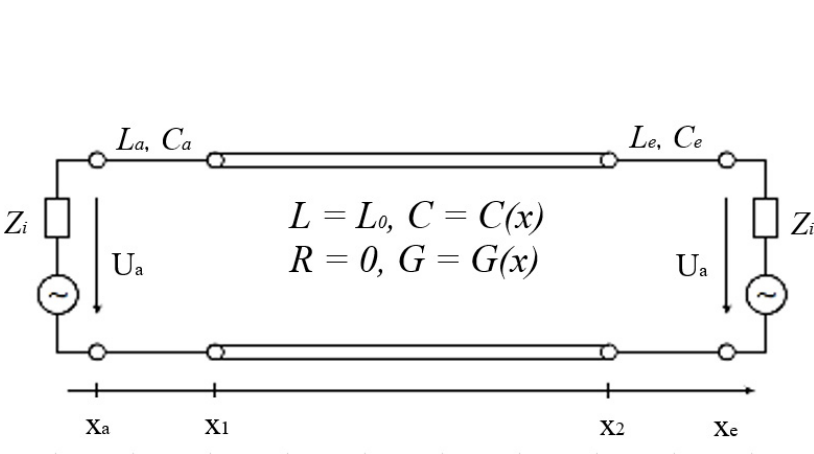

(a)

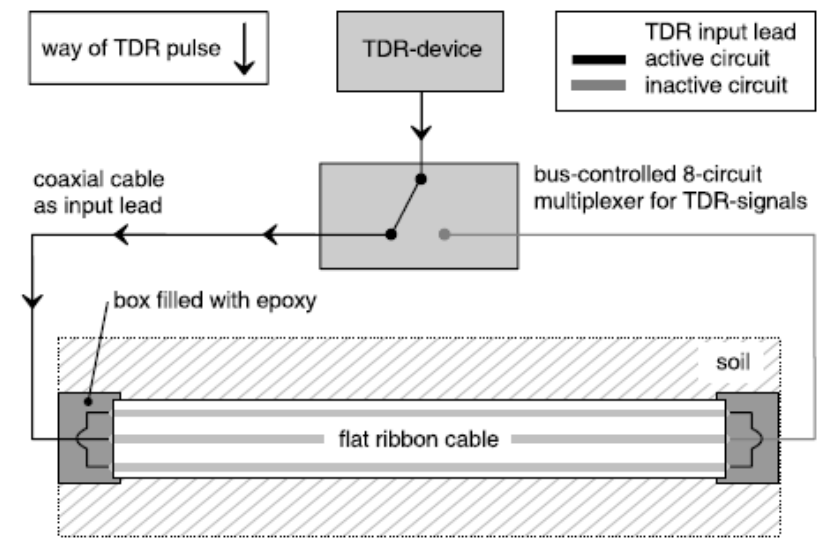

(b)

Figure 3. (a) The schematic plot of spatial TDR measuring electrical circuit with previous assumptions; the flat ribbon cable is located between $x_{1}$ and $x_{2}$, coaxial cable is between $x_{a}$ and $x_{1}$ or $x_{2}$ and $x_{e}$ [19]; (b) the implementation of two-way TDR tracing using TDR device and multiplexer [17].

\subsection{Spatial Time Domain Reflectometry Two-Way Inverse Analysis}

To extract the $C$ and $G$ profiles, the last step is the application of the optimization technique for minimizing the difference between forward modeling and TDR measurement results. Generally, for an optimization problem, the objective function is usually the square difference between prediction and measurement, starting from an initial estimation and finally determining with the global minimum. Schlaeger [19] derived the objective function as Equation (5):

$$
F(C, G)=\sum_{i=1}^{2} \int_{0}^{T}\left[U_{i}{ }^{M}\left(x_{i}, t, C, G\right)-U_{i}{ }^{m}\left(x_{i}, t\right)\right]^{2} d t
$$

where $F$ is the objective function of $C$ and $G ; U_{i}{ }^{M}$ and $U_{i}{ }^{m}$ are, individually, the predicted and measured voltage ( $i=1,2$ corresponds to two-way TDR tracing). This function has been successfully optimized using the conjugate gradient method with the reconstruction of $C$ and $G$ by Schlaeger [19]. The optimization procedure is to input one initial estimation of the $C$ and $G$ profiles into forward modeling to calculate the cost function and update the input by previous minimization outcomes until the cost function achieves the global minimum. The derivation of the Jacobin gradient of the objective function using the adjoint PDE of Equation (4) can be sourced from the mathematical study [19]. 


\subsection{Spatial Time Domain Reflectometry One-Way Inverse Analysis}

On the other hand, for the only reconstruction of the capacitance profile using one-way TDR tracing, Becker and Schlaeger [43] applied an empirical equation between $C$ and $G$ proposed by Håkansson [44]:

$$
G(C)=\left\{\begin{array}{lr}
G_{\infty} \cdot\left(1-\mathrm{e}^{\frac{C_{0}-C}{C_{d}}}\right) & \text { if } C \geq C_{0} \\
0 & \text { if } 0 \leq C \leq C_{0}
\end{array}\right.
$$

where $G$ and $C$ are the conductance and the capacitance of soil and sensor isolation, $C_{0}$ and $C_{d}$ are the fitting parameters for capacitance; and $G_{\infty}$ is the fitting parameter for the conductance. Using Equation (6), the inverse analysis only solves one TDR trace measured from each terminal, because the capacitance profile is the only unknown input in need of optimization. This relationship was successfully used for the three-pin probe sensor in the previous study of technique development [43]. In this study, the values of fitting parameters are $C_{0}=50 \mathrm{pF} / \mathrm{m}, C_{d}=40 \mathrm{pF} / \mathrm{m}$ and $G_{\infty}=90 \mathrm{mS} / \mathrm{m}$.

\subsection{Spatial Time Domain Reflectometry Post-Analysis}

Once the capacitance profile can be inversely determined using this algorithm, the permittivity profile of the surrounding soil along the sensor can be calculated in accordance with the capacitance model characterizing the cable sensor, as shown in Figure 2c. Before calculating the permittivity of the soil $\left(\varepsilon_{m}\right)$, the three capacitance values $C_{1}, C_{2}$ and $C_{3}$ ought to be experimentally calibrated. This calibration has been completed previously $($ see $[17,18])$, and the permittivity is calculated based on the capacitance model shown in Figure $2 \mathrm{c}$ as:

$$
C\left(\varepsilon_{m}\right)=\frac{\varepsilon_{m} C_{1} \cdot C_{2}}{\varepsilon_{m} \cdot C_{1}+C_{2}}+C_{3}
$$

where $C_{1}(14.8 \mathrm{pF} / \mathrm{m}), C_{2}(323 \mathrm{pF} / \mathrm{m})$ and $C_{3}(3.4 \mathrm{pF} / \mathrm{m})$ are parameters of the capacitance model, $C$ is the total capacitance of the soil and coating isolation, $\varepsilon_{m}$ is relative permittivity [17]. Eventually, the soil moisture profile can be calculated by the empirical models (Equation (2)) or the phase-mixing model (Equation (3)), which needs specific calibration using a Vector Network Analyzer (VNA) with the open-ended coaxial cell [45-47].

Instead of the reconstruction of the capacitance profile along the sensor, the travel time determined using the tangent method along one TDR trace can also be used to calculate the mean capacitance using:

$$
C\left(\varepsilon_{m}\right)=\frac{1}{L} \cdot\left(\frac{t}{2 L_{p}}\right)^{2}
$$

where $C$ is the total capacitance for the entire measuring zone, $\varepsilon_{m}$ is relative permittivity, $L$ is inductance (constant $L_{0}=756 \mathrm{nH} / \mathrm{m}$ ), $t$ is travel time and $L_{p}$ is the length of the sensor. Equation (8) is useful to validate the mean moisture content for the total measuring volume. The mean moisture content later can be determined using Equation (8) for soil permittivity with Topp's model for the moisture content calculation.

\section{Experimental Set-Up for Investigation of Soil Water Retention Behavior}

The experimental set-up mainly consists of three logging systems separately recording point-wise soil suction profile, moisture content profile and accumulative outflow. An overview of the experimental platform is shown in Figure 4a, which demonstrates the view of the experimental set-up in the Geomechanics Laboratory at Geotechnical Engineering Centre, School of Civil Engineering, University of Queensland, St. Lucia QLD, Australia.

\subsection{Soil Sample Specification}

Two types of sandy soil were involved in this experimental set-up. One is the beach sand collected from Bribe Island, and the other one is the Budget Brickies loamy sand collected from an unknown construction site, Queensland, Australia. The particle size 
of the two types of sand ranges from 0.075 to $2 \mathrm{~mm}$. The $D_{50}$ of beach sand is $0.35 \mathrm{~mm}$, which is slightly larger than the mean size of loam, $0.27 \mathrm{~mm}$. The sieving analysis was implemented for both types of sand in accordance with ASTM standards of particle analysis for coarser soil [48].

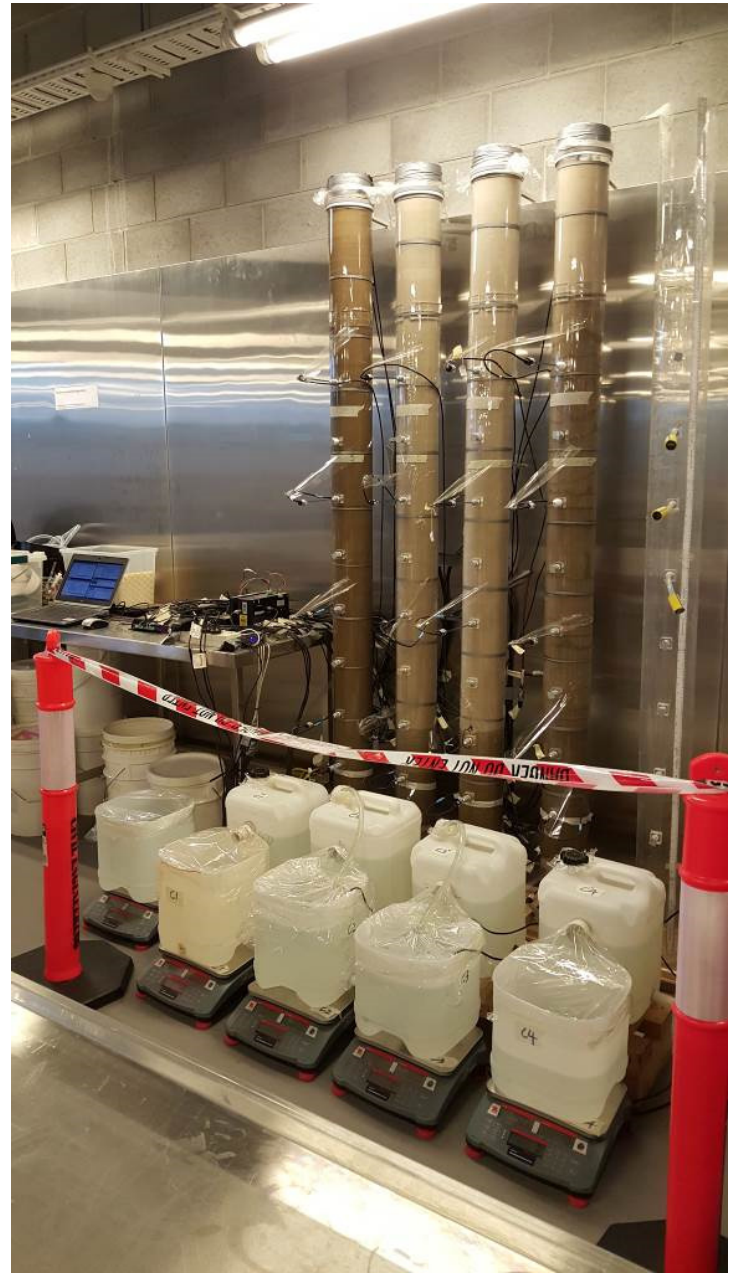

(a)

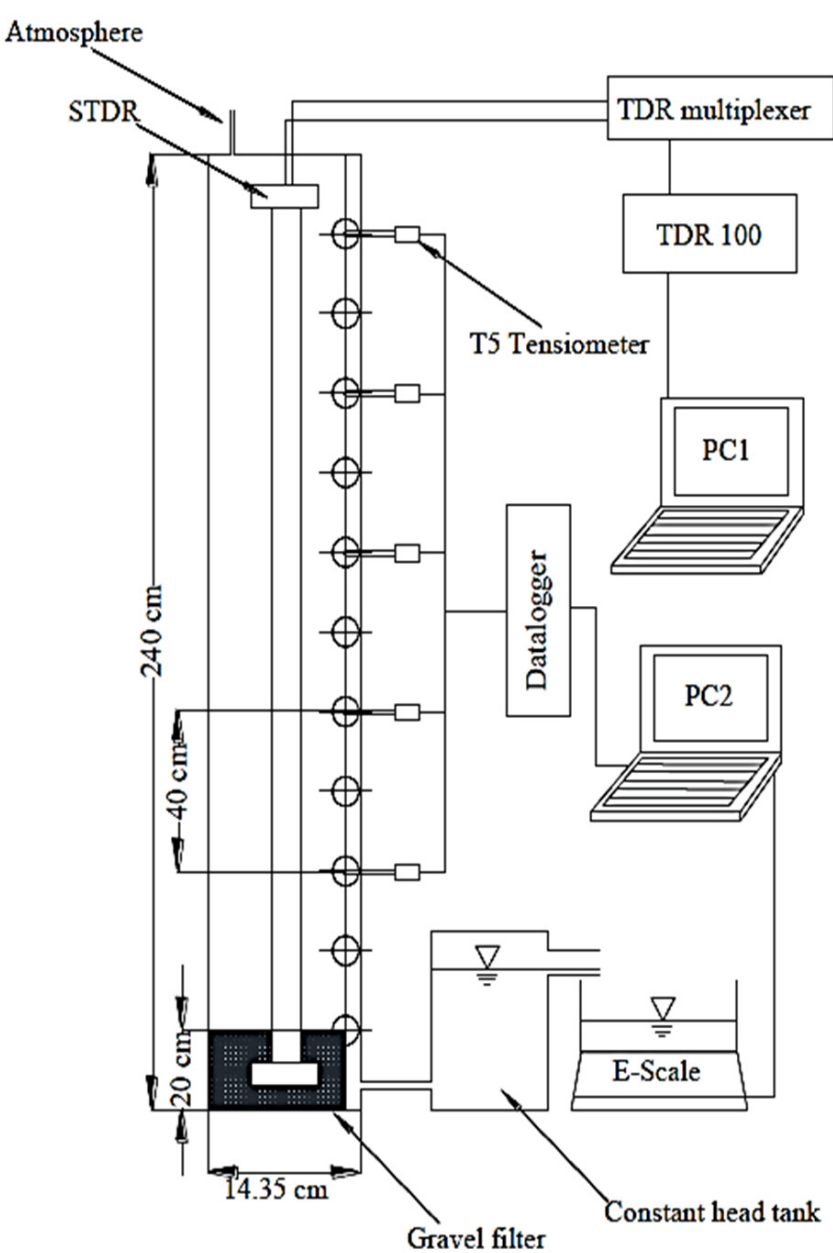

(b)

Figure 4. (a) The overview of the physical experimental set-up for gravitational drainage and spontaneous imbibition experiment; (b) the specification of sensor configuration and hydraulic boundary condition for gravitational drainage experiment.

The mineralogy of the two samples comprised of quartz at the specific gravity of 2.65. The coefficients of uniformity $\left(C_{u}\right)$ for beach sand and loamy sand are 1.71 and 2.39 separately, and the coefficients of gradation $\left(C_{c}\right)$ are 0.99 and 1.11. Based on the Unified Soil Classification System (USCS), both of them are poorly graded uniform sand (SP). The beach sand is medium sand without any fine content, while the loamy sand is fine sand with a fine content of $5 \%$. The loamy sand is adopted for a demonstration of the results collected by the experimental platform in this study.

\subsection{Moisture Profile Logging System Set-Up}

As previously mentioned, the spatial TDR technique was applied to soil moisture profile measurement; four flat ribbon cable sensors were individually inserted into the centers of four empty acrylic columns (diameter $=14.35 \mathrm{~cm}$ and length $=240 \mathrm{~cm}$ ). The bottom terminal of spatial TDR is fixed with an artificial gravel filter designed based on published criteria [49]. The falling head test was conducted on the gravel filter to confirm that the hydraulic conductivity of the filter $\left(6.5 \times 10^{-3} \sim 9.5 \times 10^{-3} \mathrm{~cm} / \mathrm{s}\right)$ was larger than the 
hydraulic conductivity of the soil specimen in the column $\left(2.9 \times 10^{-3} \sim 5.6 \times 10^{-3} \mathrm{~cm} / \mathrm{s}\right)$. It does not only indicate the end of spatial TDR but is also a highly pervious porous media under the specimen being tested. Moreover, there was no sand or fine gravel flushed out during the soil water drainage process.

Each flat ribbon cable sensor had two terminals, demanding two channels on the multiplexer. Due to the need for four sensors for four columns, a TDR trace logging system consisting of a Campbell Scientific SDM X50 multiplexer@ (8-channels) combined with both a TDR100@ and a CR1000 data logger@ was built to connect to eight connectors of four sensors. The data logging program coded in CRBasic $(\odot)$ was then applied for automatically logging eight TDR traces from 8 multiplexer channels to complete one/two-way TDR tracing in each soil column. An overview of the experimental set-up and illustration are separately shown in Figure 4a,b.

This technique and logging system have been successfully applied to soil column tests and embankment water content dynamics measurement $[17,20]$. According to previous performance measurements [17], spatial TDR can achieve a spatial resolution of $3 \mathrm{~cm}$ with an average deviation of around $\pm 2 \%$ for moisture content. The TDR100@ can only impulse into the single sensor by changing the single switch along eight multiplexer channels. Therefore, for two-way TDR tracing on each sensor, there has to be at least a one-second delay between the two occurrences of TDR pulsing. However, this is much smaller than the moisture redistribution speed in natural sand. Hence, this delay is neglected, and two-way TDR tracing could be seen as simultaneously implemented.

As a gravel filter designed based on filter design criteria [49] guarantees the lowest hydraulic resistivity impacts from the column bottom without internal erosion, the transient flow conditions in the measuring range will not encounter any artificial alleviation of flow velocity. Similar soil column experiments have been implemented by many previous studies [8,9,16,20,50-53]. With the exception of the 2-m soil column test [51], most of them, conducted in shorter soil columns of less than $1.2 \mathrm{~m}$, required a hanging column method with a water table below the bottom of the specimen. In this case, there has to be a high air entry (HAE) porous media under the specimen to build up the hydraulic connectivity between the specimen and water reservoir for suction control. To avoid air penetrating through the HAE disk to subsequently disconnect the suction-applying reservoir from the system, such disks or membranes must possess a smaller pore size distribution (PSD), which is much smaller than the specimen. Usually, the HAE disks are ceramic disks made of clay particles sintered together. Thus, the hydraulic conductivity of the HAE material is much lower than the sandy soil specimen. It is somehow inevitable to generate a quasisteady-state flow condition using a shorter soil column test with the adoption of an HAE disk. Additionally, such smaller column tests only allow the measurement of half of the suction and moisture profile. In this experiment, due to the use of a 2.4-m-long column with a gravel filter fixing the spatial TDR sensor to the column bottom, there was an opportunity to neglect those artificial constraints in previous experimental set-ups. On the other hand, the previous 2-m soil column test applied the oven-drying method for determining the segments of the soil column only after equilibrium was achieved [51]. In comparison to the previous study, the current experimental set-up in this study can provide moisture measurement with a high temporal and spatial resolution by applying the spatial TDR technique. These advantages demonstrate the novelties of this experimental platform.

\subsection{Suction Profile Logging System Set-Up}

There were five UMS T5 tensiometers@ (Figure 5a) inserted into the unsaturated zone at the elevations of $40,60,100,140,180 \mathrm{~cm}$, where all were the above constant water pressure head of $36 \pm 1 \mathrm{~cm}$, as shown in Figure $4 \mathrm{~b}$. Moreover, there is another tensiometer inserted into the saturated zone under the water table at the elevation of $20 \mathrm{~cm}$, which is not specified in Figure 4b. There is a spatial resolution of $20 \mathrm{~cm}$ for suction profile logging at the column bottom in order to detect the dynamic pore water pressure around the capillary fringe area for the future investigation of SWRC dynamic effects under 
variable water pressure boundary conditions. In total, there are twenty-four sensors on four columns (six sensors on each column). These sensors are connected to one Geo-Datalogger (DT85G, Pacific Data(C). The temporal resolution of data logging is set to $30 \mathrm{~s}$. As the UMS T5 tensiometers used a Wheatstone bridge circuit (Figure 5b), according to the logger manual [54], the output value of this data logger is:

$$
B_{\text {out }}=\frac{V_{\text {out }}}{V_{\text {ex }}} \cdot 10^{6}
$$

where $B_{\text {out }}$ is the dimensionless voltage, $V_{\text {out }}$ is the measured bridge output voltage, $V_{e x}$ is the excitation voltage. In addition, the T5 sensor measuring range is from $-85 \mathrm{KPa}$ for suction up to $+100 \mathrm{KPa}$ for positive water pressure. Thus, calibration between the dimensionless voltage and water pressure was carried out for each sensor within the positive water pressure range. Due to the perfect linear equation fitting into the calibration data points in Figure 5b, the calibration equation can be applicable for the entire measurement range. Twenty-four sensors share the same slope in the linear calibration equation, except for differences in the interception $(-0.2 \sim 1.5 \mathrm{kPa})$ due to the varying physical offset on each sensor. It should be noted that the physical offset depends on the maintenance of the T5 sensors. After storing them for a long period, the calibration has to be reconducted to determine the new offset values due to the aging issue of the membrane in the sensor body. When the water table drops to the hydraulic head of the constant head tank, and equilibrium is approached, the suction value can also be double-calibrated and validated by calculating the suction head above the groundwater table. Meanwhile, the trend of the dynamic response of pore pressure can also be collected under the transient flow condition. The specification of the T5 tensiometer is summarized in Table 1.

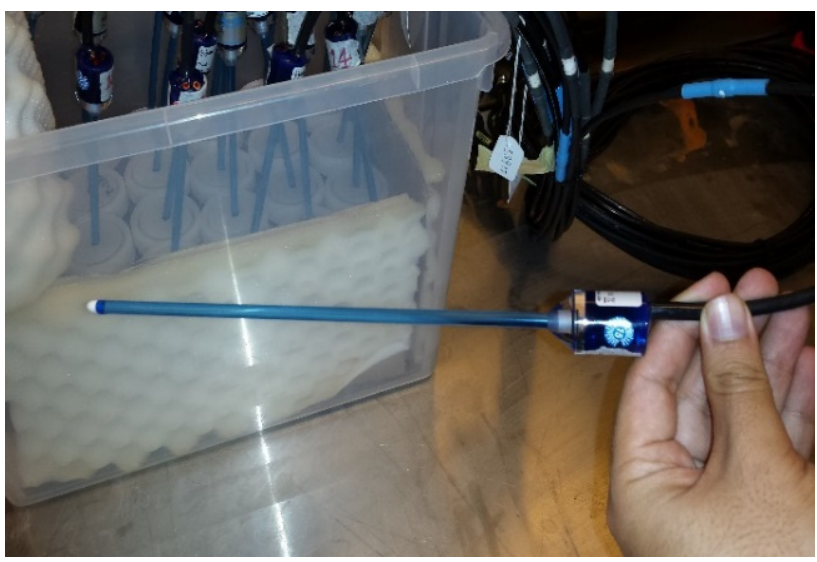

(a)

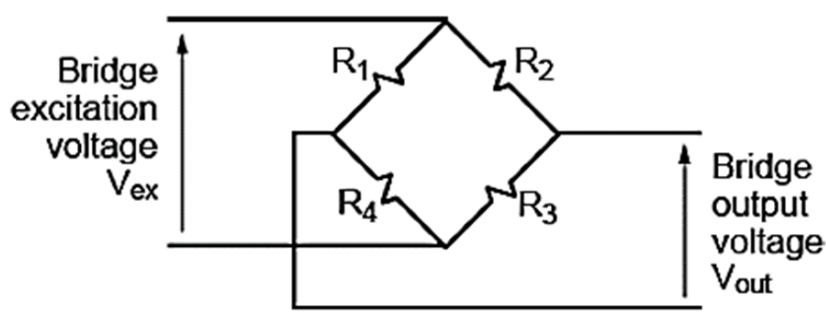

(b)

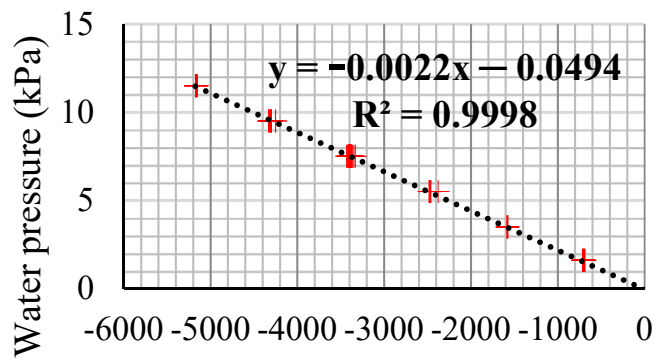

Dimensionless Voltage (ppm)

(c)

Figure 5. (a) UMS T5 tensiometer with a 20-cm shaft (deionized water fully filled) [53]; (b) the electrical circuit of T5 tensiometer [54]; (c) the linear calibration between dimensionless voltage bout and water pressure (the red crosses are data measured for calibration using linear regression) [53]. 
Table 1. Specification of UMS T5 micro-tensiometer [55].

\begin{tabular}{cc}
\hline Specification & Range \\
\hline Measuring range & $+100-85 \mathrm{kPa}$ \\
Precision & $\pm 0.5 \mathrm{kPa}$ \\
Shaft diameter & $5 \mathrm{~mm}$ \\
Shaft length & $20 \mathrm{~cm}$ \\
Output signal & $-100 \mathrm{Mv}+85 \mathrm{mV}$ \\
\hline
\end{tabular}

For an investigation of the soil suction profile in transient flow conditions, the response delay of the pressure sensor is of particular concern. The response time of tensiometers was fully investigated by Klute et al. [56]. For every tensiometer, there will be a time delay in the pressure response between the specimen and sensor body because of the permeability of the ceramic cup on the shaft tip. However, because the T5 sensor only measures a low suction range and the thickness of the ceramic cup is smaller than the HAE disk, there is only minor hydraulic resistance between the sensor and specimen. According to the T5 tensiometer manual [55], it only takes 5 seconds to approach an accurate value, and this is already the fastest option for suction measurement among other methods requiring moisture redistribution in a long equilibrium period, such as filter paper, dew point meters and ATT $[1,2,57]$. As the temporal resolution of suction logging is 30 seconds, such a small delay in response can be neglected for this experimental set-up.

\subsection{Outflow Logging Set-Up, Initial and Boundary Conditions}

There are four bench scales used to log accumulative outflow. As illustrated in Figure 4c, a constant head tank is attached to the output at the bottom of the column. The overflow of the constant head tank is collected by another water tank located on an electrical bench scale. In the case of evaporation leading to underestimation of outflow, every tank is covered by cling wraps with holes only for flow conduits. In Figure $4 a, b$, four bench scales are all connected to a USB hub with a data transmission cable between RS232 and a USB interface. In Figure $4 b$, one extra tank on the bench scale is located in the leftmost position with exactly the same ambient conditions to measure the water evaporation for moisture loss compensation. The maximum capacity of the bench scale (Ohaus Ranger $3000 \mathrm{R} 31 \mathrm{P} 30 \odot$ ) is $30 \mathrm{~kg}$, with a precision of $\pm 1 \mathrm{~g}$. The logging time step is also set at $30 \mathrm{~s}$. On the other end of the column, cling wrap was also used to fully cover the open top of the soil column with a small pinhole to apply atmospheric pressure. The initial condition was to retain the water table. Since the valve between the constant tank and the saturated sand column was opened, the experiment was initiated. The data logging system was turned on only a few minutes before.

\subsection{Specimen Installation and Operating Procedure}

The density control of sand specimen installation in the column was conducted by tamping on the side of the acrylic column and vertically compacting on top of each layer. The top and bottom of each column were fixed to be exactly vertical to avoid tilting off during compaction and any inclines afterwards. In regard to minimizing the density variation along such a long column, the thickness of each soil layer was controlled to $22 \pm 1 \mathrm{~cm}$. With the same inner diameter of the column, it was possible to achieve a mean dry density of $1.61 \pm 0.05 \mathrm{~g} / \mathrm{cm}^{3}$ (porosity $39 \% \pm 2 \%$ ) for beach sand and $1.45 \pm 0.1 \mathrm{~g} / \mathrm{cm}^{3}$ (porosity $45 \% \pm 4 \%$ ) for loamy sand. The water used for fabricating this saturated specimen was tap water from the Geomechanics Laboratory of the University of Queensland, St. Lucia QLD, Australia, due to a lack of access to a large amount of de-aired water produced close by. However, it is non-saline water for general purpose. Under a low suction range for sand soil $(0 \sim 22 \mathrm{kPa})$, soil water temperature $22 \pm 1{ }^{\circ} \mathrm{C}$ and normal room temperature $23 \pm 1{ }^{\circ} \mathrm{C}$, there should be no further issue regarding nucleation, such as cavitation and boiling. The segmentation of each layer was carefully controlled to mismatch each pinhole for tensiometer insertion. A previous soil column test mentioned two approaches for 
tensiometer installation: installing a sensor through a pre-drilled hole or installing a sensor during the compaction process [58]. Here, the T5 sensors were all inserted into the column during the compaction process. Compared to the first method, the second ensures perfect contact between each sensor and ambient soil [58]. The gap between each sensor and pinhole was sealed with both a waterproof rubber O-ring and gas leakage-free thread tap. Each T5 sensor was originally filled with deionized water using an automatically de-aired water refilling kit, manufactured by $\mathrm{UMS}^{\circledR}$. Except for the occurrence of the ceramic tip dried out for soil gas percolation, there will be bubble-free water in the sensor and shaft up to $-101 \mathrm{KPa}$ by mechanical vacuuming.

For the gravitational drainage test, the soil was oven-dried before loading into the column to avoid soil segregation carrying bubbles inside the microscale soil structure. Beach sand is completely cohesionless sand. Once the sample was oven-dried, there was no more segregation, while the loamy sand needed some crushing and mechanical shaking because of slightly cohesion. The water table was always above each layer that was being compacted for the preparation of the saturated specimen. The spatial TDR sensor was located in the center of the column, with good contact between soil and sensor, so there should be no more concerns about the failure of the spatial TDR technique because of gaps between the soil and sensor [37] and inductance variation due to distortion of the sensor geometry [17].

\section{Results and Discussion}

This experiment was originally designed to investigate the dynamic effects in SWRC [11], the hydraulic properties of unsaturated soil and the validity of the theories of two-phase flow in porous media for the transient flow condition [59-61]. Thus, this experimental platform will be used for different hydraulic boundary conditions in a sequence of the constant head, multistep in/outflow by head control. Currently, as the first stage of the constant head boundary, this experiment was conducted to assess gravitational drainage in a fully saturated sample and spontaneous imbibition to fully dry sample, which needs several months to reach equilibrium conditions without further moisture/suction variation.

However, some results regarding gravitational drainage only took a few weeks to approach equilibrium. Therefore, this part of the results is presented as a demonstration of the experimental platform's success in this study. Comparison between this soil column test and the standard hanging column test for loamy sand is also given to depict the difference and discussion is dedicated to identifying the potential problems in the conventional testing technique. Prior to the measurement of SWRC, the spatial TDR measurement and analysis are conducted to highlight the difficulties and problems in the post-analysis of spatial TDR waveforms.

\subsection{Spatial TDR Tracing during Water Table Decreasing}

When this experimental platform was firstly set up, before loading the sample into the column, some previous tests were conducted to validate the signal variation of TDR traces. Thus, a pre-test was completed by dropping the water table for a single column from an originally saturated condition in order to characterize the decrease in the reflection coefficient along TDR waveforms. An illustration of this pre-test is shown in Figure 6a and the TDR traces for different water tables are shown in Figure 6b. With the water table dropping downward, the TDR traces logged from 0 to 3 min clearly show an increase in the reflection coefficient along the flat ribbon cable measured from the top. After four min, the water table is stable since no variation in the TDR waveform is visible.

\subsection{Spatial TDR Waveform Variation along the Sand Column in the Drainage Test}

The TDR traces for the gravitational drainage test are shown in Figure 7. Two TDR pulses are separately sent to the sensor in the column from the top and bottom. A pair of TDR traces measured from both ends of the sensor at the same time can be used to conduct the inverse analysis. According to Figure 7a (Terminal Top) and b (Terminal 
Bottom), it is clear that the reflection coefficient of TDR traces increases with the falling water table and water draining out of the soil column. Since air enters the pore space at the top end of the column with the dropping of the water table, TDR traces measured from the top and end show an increase in the reflection coefficient up to 0.3. Meanwhile, the second reflection points in these TDR traces, indicating the transition between the sensor and the second coaxial cable, decrease from 110 to $100 \mathrm{~ns}$. The TDR traces measured from the bottom display significant changes at the end of the TDR trace, showing a more pronounced transition from the sensor to a coaxial cable (drop after the second rise in the signal). The comparison of the signals demonstrates the strong variation in the TDR traces, corresponding to the change in the moisture profile. It further proves the capability of the spatial TDR technique for characterizing information on moisture content dynamics in large-scale unsaturated soil experiments.

\subsection{Validation of Spatial TDR by Outflow Logging}

The measurement from the spatial TDR sensor was firstly validated by the outflow data logged using an electrical bench scale. First, the tangent method was used to determine the travel time for each TDR trace sent from the column bottom. Second, the previously determined travel time was used to calculate the total mean capacitance using Equation (8). Then, the real part of soil permittivity can be calculated using Equation (7). Finally, the volumetric moisture content is calculated by Topp's model in Figure 8. Based on the outflow and volume of the specimen, the mean volumetric moisture content was eventually calculated and plotted in Figure 8. The moisture prediction from the spatial TDR sensor strongly agrees with the moisture content calculated from the outflow data. This demonstrates the success of electrical design with corresponding parameter calibration of the spatial TDR sensor and the applicability of Topp's model for this loamy sand.

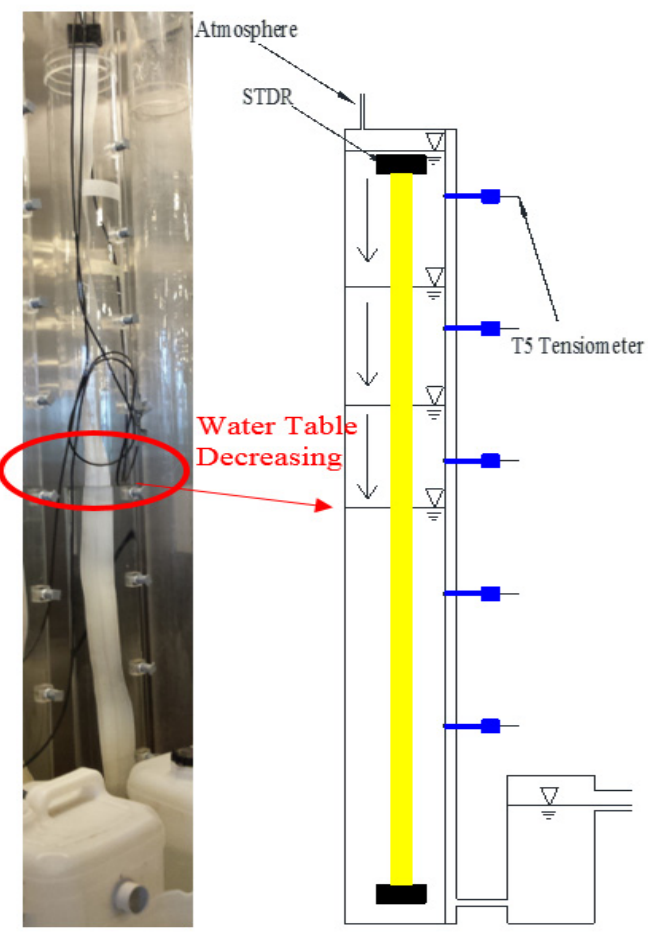

(a)

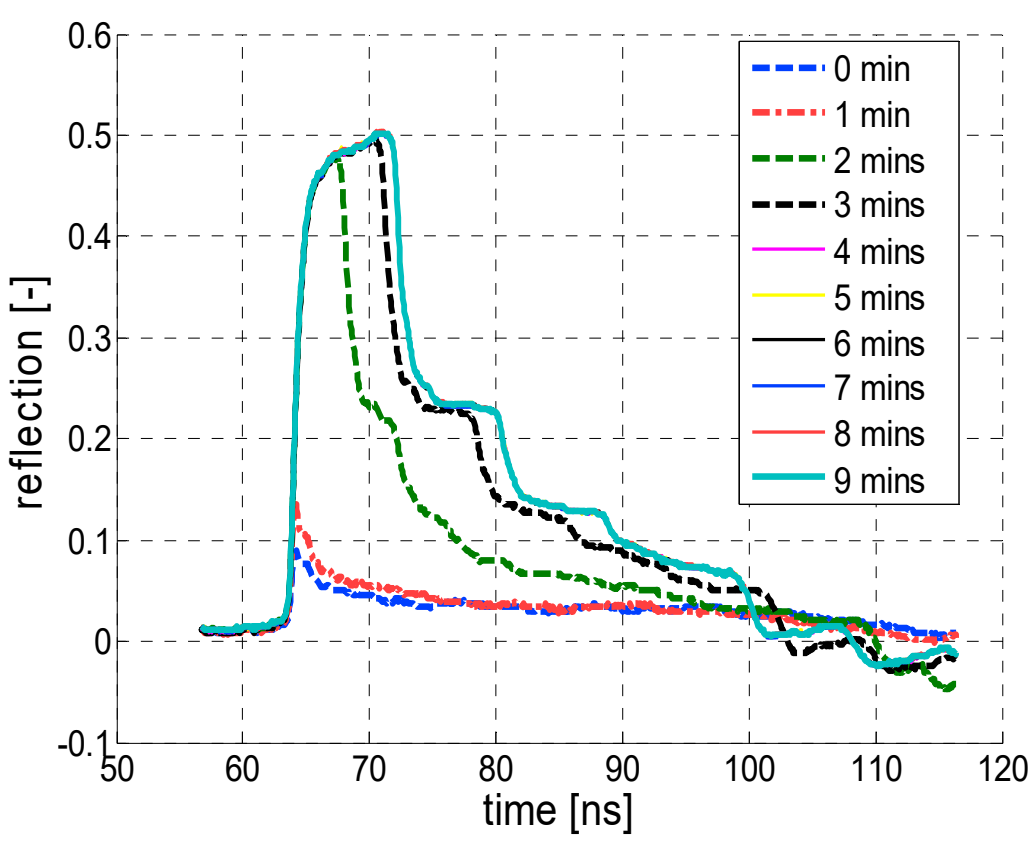

(b)

Figure 6. (a) The illustration of a single column drainage test without sample filled; (b) TDR waveforms indicating a drop in water table [62]. 


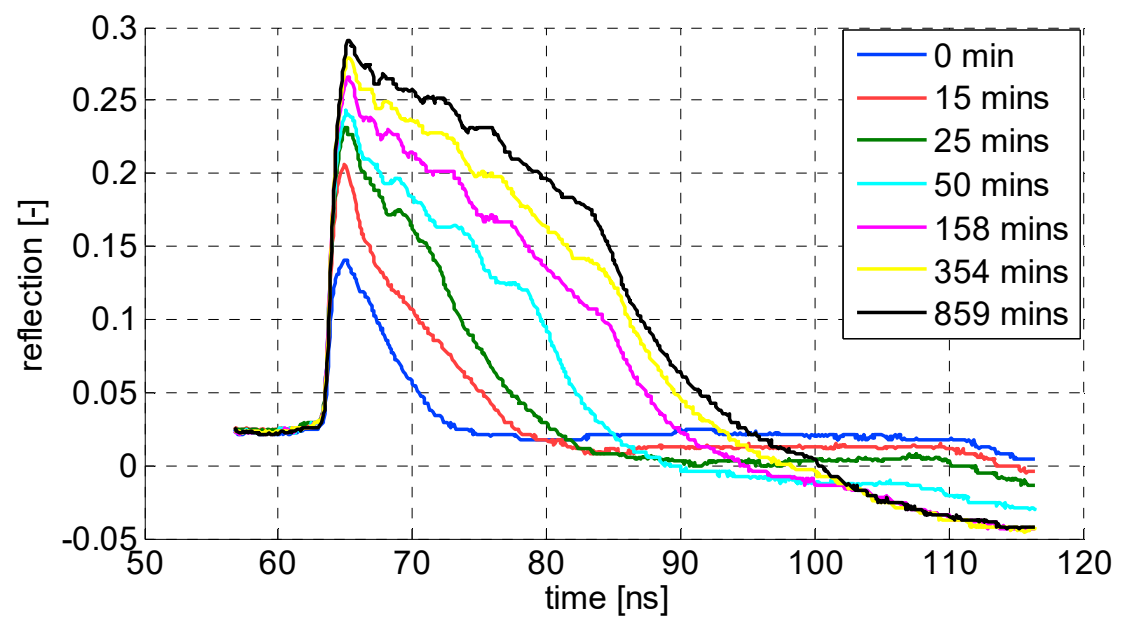

(a)

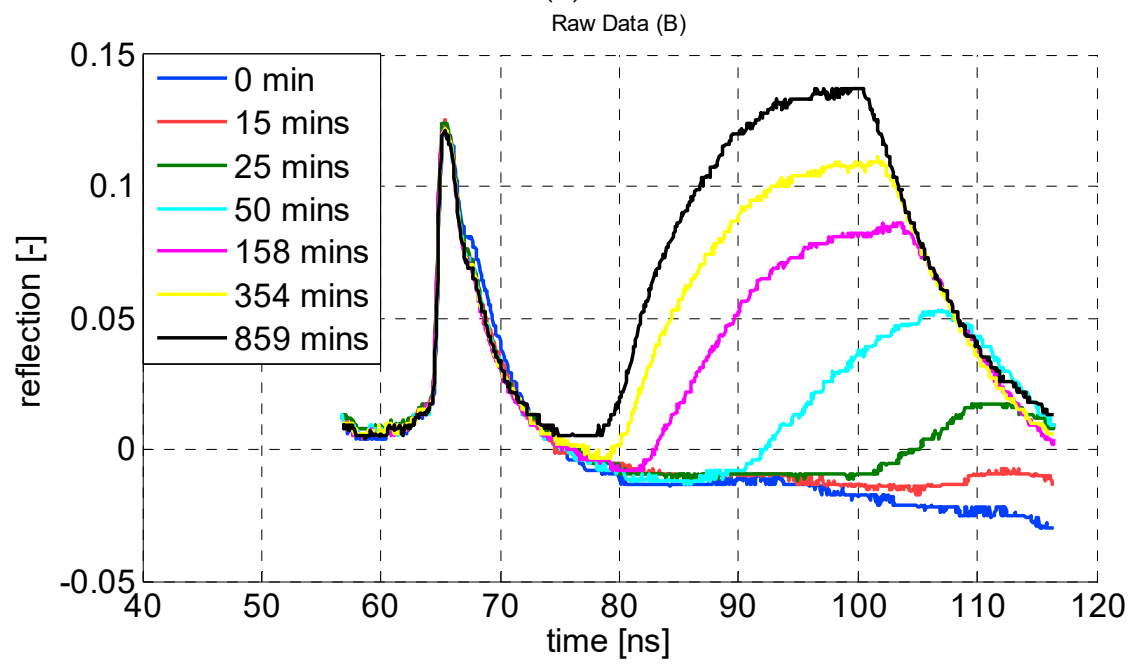

(b)

Figure 7. TDR traces for gravitational drainage test: (a) TDR traces measured from the top; (b) TDR traces measured from the bottom [62].

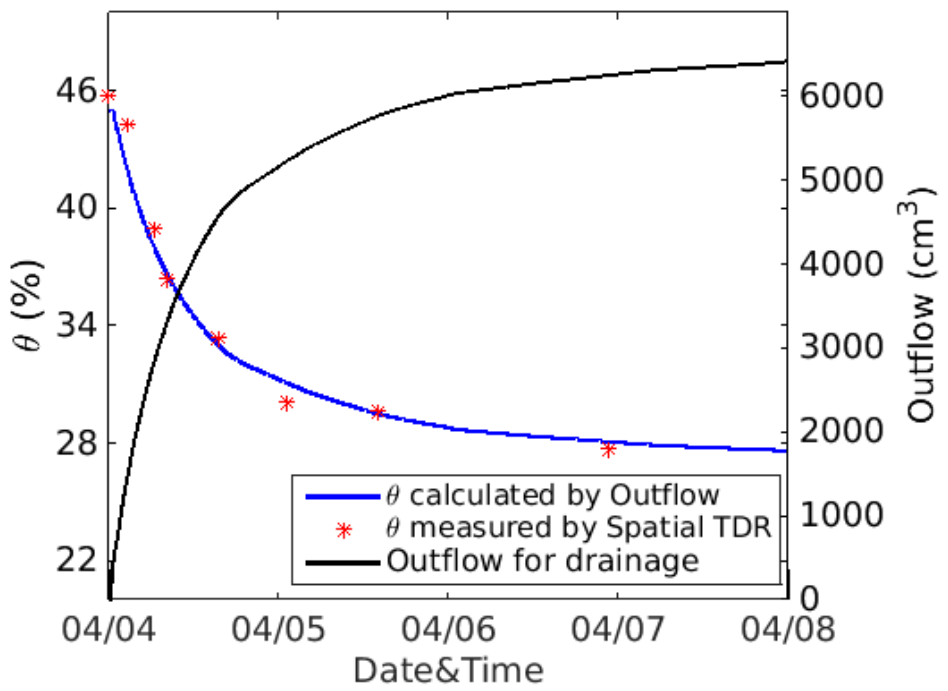

Figure 8. The mean water content dynamics for the loamy sand column in comparison with the mean water content from outflow data. 


\subsection{Inverse Analysis of Spatial TDR Trace and Dynamic Moisture Profile}

Figure 9a shows the performance of optimization using one-way inverse analysis of the spatial TDR technique. By applying the optimization, the TDR traces simulated using the forward modeling telegraph equation can be well-matched with the TDR traces measured using the data logging system. Based on this acceptable fitting performance, the dynamic moisture profile can be finally calculated using Topp's model, as shown in Figure $9 \mathrm{~b}$. From the beginning at 12:00 pm on 4th April, the moisture content profile was fully saturated, with a mean moisture content of around $45 \%$. Once the one-step gravitational drainage commenced, the pore water in the upper zone drained fast in the first $8 \mathrm{~h}$. After two days, by 1:56 am on 6th April, it almost achieved the equilibrium condition. The data logging from the two following days shows no significant variation in moisture profiles, indicating the final equilibrium condition achieved.

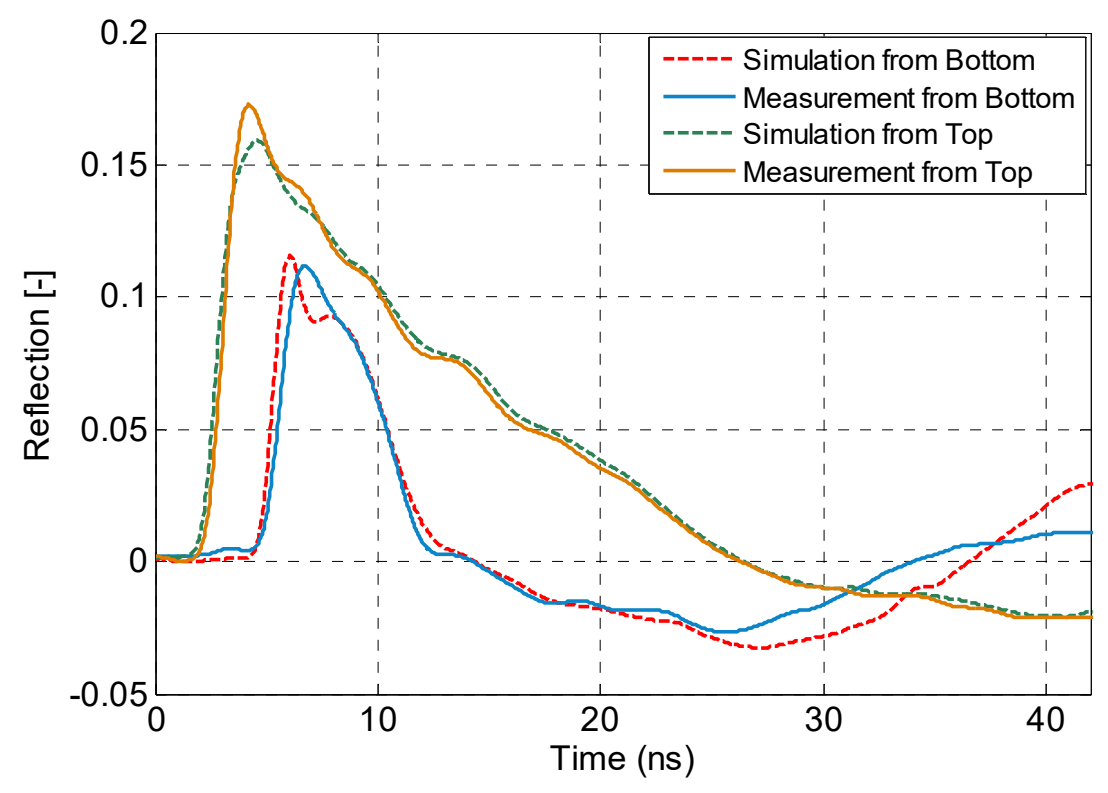

(a)

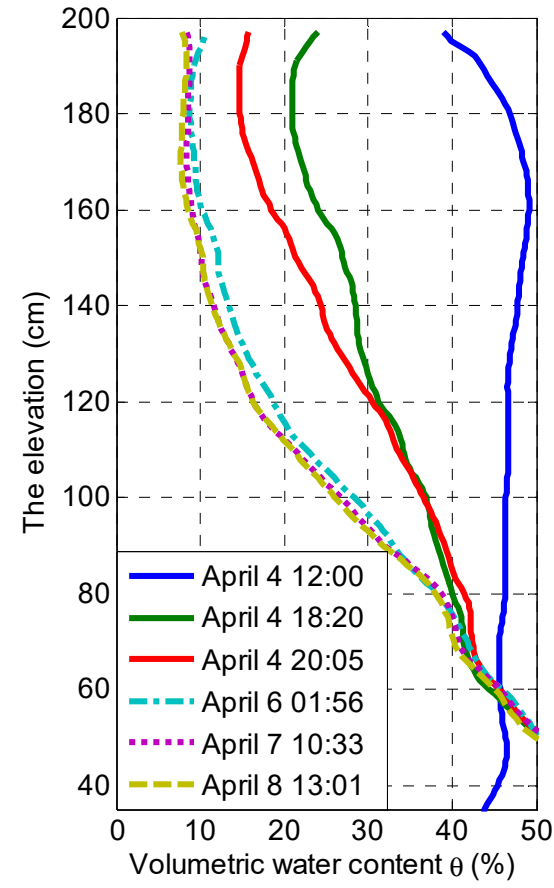

(b)

Figure 9. (a) The fitting performance of capacitance reconstruction using one-way inversion analysis on both terminals (TDR trace sent from bottom and top); (b) the dynamic volumetric moisture content profile measured using the spatial TDR inverse analysis.

It should be noted that there is an overestimation of moisture in the capillary fringe zone because of the transition zone between the sensor and epoxy terminals. Thus, it should not be used for the determination of saturated moisture content. Instead, the saturated moisture content at the initial condition should be used to cut off the irresponsible partition to determine both the air entry value (AEV) and moisture profile in the saturated area. These series of dynamic moisture profiles demonstrate the success of inverse analysis of spatial TDR technique functioning in principle, while more effort might be required to enhance the optimization method and take consideration of frequency dependence for measuring more conductive porous media.

\subsection{Validation of Pressure Measurement and Dynamic Response of Water Pressure}

Figure 10a shows the good agreement between the measured suction and theoretical water pressure calculated using the hydrostatic concept at the equilibrium stage. It proves the accuracy of the previous linear calibration between value $B_{\text {out }}$ and water pressure for 
the T5 tensiometer with the datalogger. Figure 10b gives the dynamic response of measured suction for one-step drainage for six months. In the first six hours, the water pressure sharply decreased from positive values to the negative, indicating soil suction.

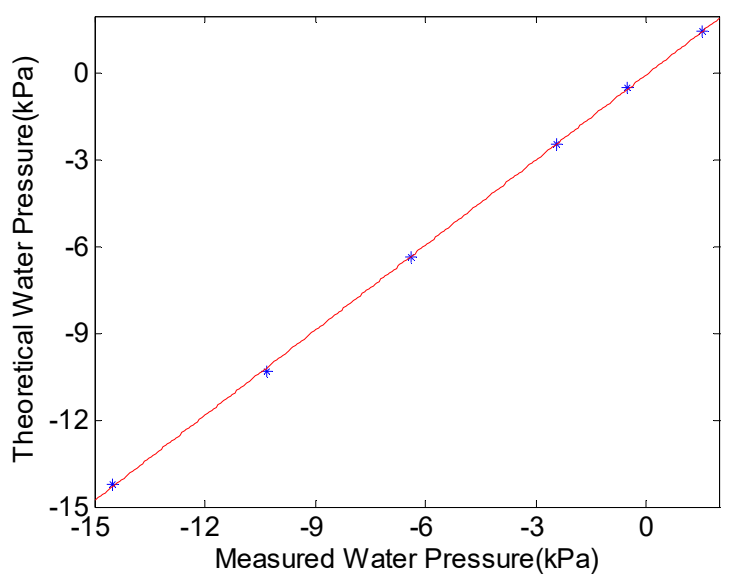

(a)

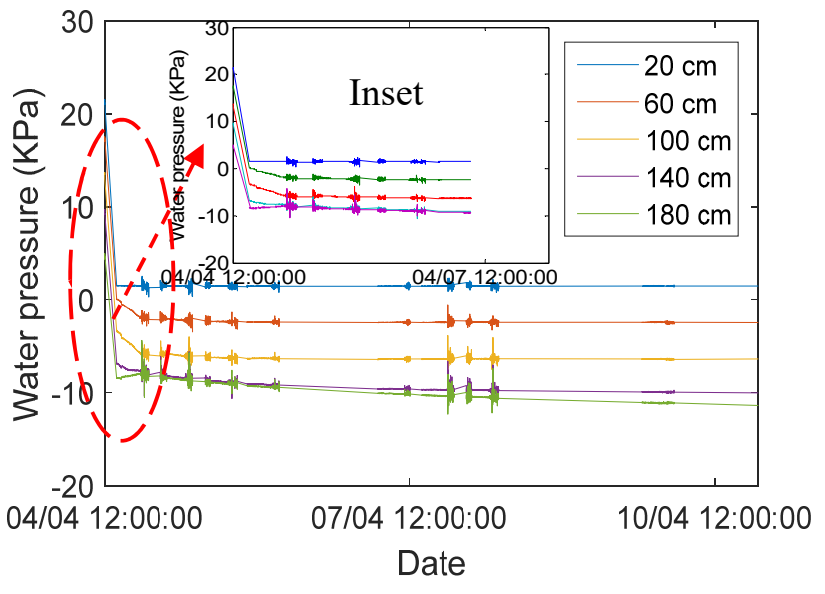

(b)

Figure 10. (a) The comparison between tensiometer measurement and theoretical water pressure; (b) the dynamic response of tensiometer on each point.

A few days later, the pore water pressure still gradually dropped to equilibrium. For the rest of the six-month period, only the suction value from the tensiometer inserted at $180 \mathrm{~cm}$ continually decreased. This further reduction for such a long period might be due to the inevitable evaporation on the upper layer, while there were two more soil layers covered by the cling wrap over the measured zone to alleviate the impacts of subsurface evaporation. The suction logging system properly functions for this drainage test, and the dynamic behavior of negative pore pressure can be successfully recorded using this experimental platform.

\subsection{Soil Water Retention Curve Measurement Compared to SWRC Using the Standard Method}

Finally, the suction and moisture logging collected at equilibrium are used to plot the SWRC shown in Figure 11 in comparison to the SWRC measured by the standard hanging column method. In Figure 11, there is a slight difference in initial density between the two methods of around $2-3 \%$. The zone of residual moisture content is around $8-9 \%$ for both methods, whereas the capillary storage (moisture content changing with soil suction) and AEV show significant differences between these two methods. Even the porosity controlled for the standard method is higher, the AEV is $1.5 \mathrm{kPa}$ higher than the AEV by the large column test. In fact, the larger porosity should provide a smaller AEV.

Moreover, due to the smaller AEV achieved in the large column test, the slope of SWRC is extended, so there is rather a gradual reduction in moisture content by increasing the soil suction than the sharper wetting front measured by the standard hanging column method. Previous studies on the spatial variation in suction calculated using the height difference between a ceramic disk and water table have demonstrated the sensitivity of suction determination by varying the specimen thickness [9]. This is reconfirmed again in our experimental exploration as one of the initiative motivations of this experimental study.

However, it is still not possible to thoroughly conclude the failure or inaccuracy of using the standard method due to the insufficient repetition for constructing such a large experimental operation. Furthermore, for a non-deformable soil matrix, the initial density control determines the pore size distribution, which governs the static SWRC and AEV $[63,64]$. This could be also a reason for the differences. This trial still further upgrades our understanding of SWRC regarding the spatial variation in suction and 
moisture. There will be a higher expectation that with further repetition of the same test in the laboratory and field, with systematic control of impact factors from environmental conditions and better precision of moisture given by the inverse analysis of the spatial TDR technique, the dynamic and spatial effects of SWRC can be more comprehensively unveiled for better two-phase flow seepage simulation, unsaturated soil strength estimation and deformation prediction.

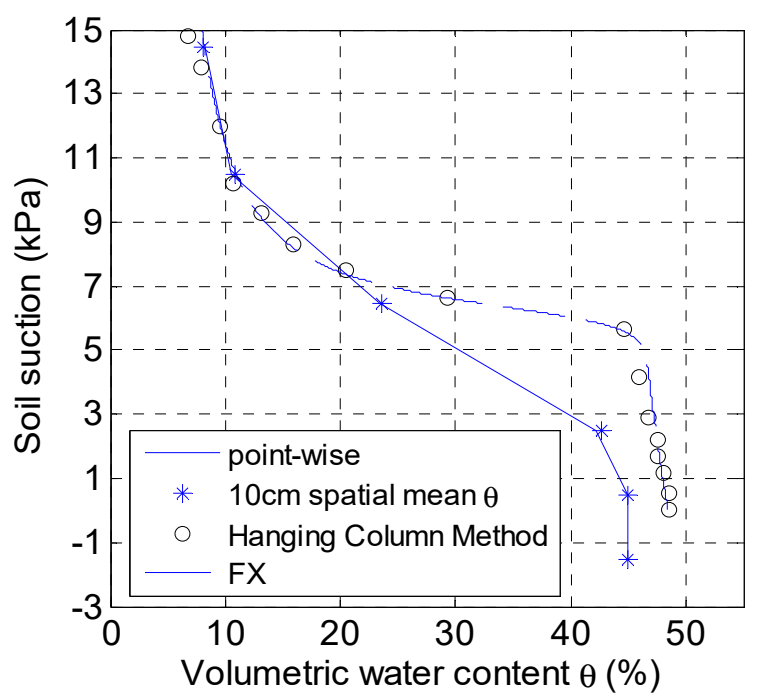

Figure 11. The comparison between SWRC measurements from the large soil column test (the mean $\theta$ averaged spatially $\pm 5 \mathrm{~cm}$ ) and standard hanging column method (the data points given by the hanging column method are fitted using Fredlund and Xing (FX) model [63]).

\section{Summary and Reflection}

The soil water retention curve (SWRC) is one of the most important constitutive relationships for the simulation of the hydraulic and mechanical behavior of unsaturated soil. As unsaturated soil effective stress, shear strength, earth pressure, consolidation and swelling are highly governed by both the soil moisture content and suction, the pre-estimation of the air-water seepage process determines the accuracy of estimating unsaturated soil's mechanical behavior. Due to this prior importance, it is critical to comprehensively investigate the dynamic and spatial effects of soil suction and moisture redistribution because many previous studies indicate such a difference between static and dynamic measurement.

This study integrates the spatial time domain reflectometry technique, high-precision tensiometer and consistent outflow logging to investigate the dynamic response of moisture distribution, soil suction and seepage flux during a transient drainage process. As the first stage, the experimental platform has been validated by the comparison between each pair of logging systems. This demonstrates the validity and functionality of this dynamic SWRC testing platform for specific loamy sand. The preliminary result shows that this system can be applied to capture both the dynamic response and the final equilibrium stage. The SWRC measured at the final stage is compared to the SWRC using the standard hanging column method, and there is a significant difference in air entry values and capillary storage between two methods. This finding further motivates the investigation of spatial effects in suction determination regarding the flaws embedded in the conventional testing method.

On the other hand, even though this experimental set-up involves excellent techniques to consistently log three state variables, the complexity of the sensoring technique and logging system leads to difficulty regarding sufficient replication in a short period. The dynamic behavior of SWRC under draining conditions needs further analysis, and the corresponding measuring technique can still be improved in future experimental investigation. In principle, the application of the spatial TDR technique offers the researcher a higher 
resolution of moisture distribution varying with time, and in principle, it functions for this experimental set-up. With a great appreciation of the TDR technique development, the hydrologist and geotechnical engineer can have a better understanding of the unobservable phenomenon that is not considered in the conventional theoretical framework.

Author Contributions: Conceptualization, G.Y., Z.L. and L.L.; Data curation, T.B.; Formal analysis, G.Y. and T.B.; Investigation, Z.L., T.B. and A.S.; Methodology, T.B., A.S. and S.S.; Project administration, L.L.; Resources, T.B.; Supervision, A.S. and L.L.; Writing-original draft, G.Y.; Writing-review \& editing, T.B. and A.S. All authors have read and agreed to the published version of the manuscript.

Funding: This research was funded by Linkage Project (LP120100662), from Australian Research Council. The APC was funded by the University of Queensland International Scholarship.

Institutional Review Board Statement: Not applicable.

Informed Consent Statement: Not applicable.

Data Availability Statement: Not applicable.

Acknowledgments: The first author would like to acknowledge support from the Geomechanics Laboratory of the University of Queensland, Australia and also thanks for anonymous reviewers.

Conflicts of Interest: The authors declare no conflict of interest.

\section{References}

1. Fredlund, D.G.; Rahardjo, H. Soil Mechanics For Unsaturated Soils; John Wiley: New York, NY, USA, 1993.

2. Lu, N.; Likos, W.J. Unsaturated Soil Mechanics; John Wiley: New York, NY, USA, 2004.

3. Khalili, N.; Khabbaz, M. A unique relationship of chi for the determination of the shear strength of unsaturated soils. Geotechnique 1998, 48, 681-687. [CrossRef]

4. Vanapalli, S.; Fredlund, D. Comparison of different procedures to predict unsaturated soil shear strength. Geotech. Spec. Publ. 2000, 195-209. [CrossRef]

5. Terzaghi, K.; Terzaghi, K.; Engineer, C.; Czechoslowakia, A.; Terzaghi, K.; Civil, I.; Tchécoslovaquie, A.; Unis, E. Theoretical Soil Mechanics; John Wiley: New York, NY, USA, 1943; Volume 18th.

6. Bear, J. Dynamics of fluids in porous media. Soil Sci. 1975, 120, 162-163. [CrossRef]

7. ASTM D2216-10. Standard test methods for laboratory determination of water (moisture) content of soil and rock by mass. Am. Soc. Test. Mater. (ASTM) 2010. [CrossRef]

8. Bottero, S.; Hassanizadeh, S.M.; Kleingeld, P. From local measurements to an upscaled capillary pressure-saturation curve. Transp . Porous Media 2011, 88, 271-291. [CrossRef]

9. Sakaki, T.; Illangasekare, T.H. Comparison of height-averaged and point-measured capillary pressure-saturation relations for sands using a modified Tempe cell. Water Resour. Res. 2007, 43. [CrossRef]

10. Barenblatt, G. Filtration of two nonmixing fluids in a homogeneous porous medium. Fluid Dyn. 1971, 6, 857-864. [CrossRef]

11. Hassanizadeh, S.M.; Celia, M.A.; Dahle, H.K. Dynamic effect in the capillary pressure-saturation relationship and its impacts on unsaturated flow. Vadose Zone J. 2002, 1, 38-57. [CrossRef]

12. Das, D.B.; Mirzaei, M. Dynamic effects in capillary pressure relationships for two-phase flow in porous media: Experiments and numerical analyses. AIChE J. 2012, 58, 3891-3903. [CrossRef]

13. Scheuermann, A.; Galindo-Torres, S.; Pedroso, D.; Williams, D.; Li, L. Dynamics of water movements with reversals in unsaturated soils. In Proceedings of the 6th International Conference on Unsaturated Soils, UNSAT, Sydney, Australia, 2-4 July 2014; pp. 10531059.

14. Sakaki, T.; O'Carroll, D.M.; Illangasekare, T.H. Direct quantification of dynamic effects in capillary pressure for drainage-wetting cycles. Vadose Zone J. 2010, 9, 424-437. [CrossRef]

15. O'Carroll, D.M.; Phelan, T.J.; Abriola, L.M. Exploring dynamic effects in capillary pressure in multistep outflow experiments. Water Resour. Res. 2005, 41. [CrossRef]

16. Mirzaei, M.; Das, D.B. Experimental investigation of hysteretic dynamic effect in capillary pressure-saturation relationship for two-phase flow in porous media. AIChE J. 2013, 59, 3958-3974. [CrossRef]

17. Scheuermann, A.; Huebner, C.; Schlaeger, S.; Wagner, N.; Becker, R.; Bieberstein, A. Spatial time domain reflectometry and its application for the measurement of water content distributions along flat ribbon cables in a full-scale levee model. Water Resour. Res. 2009, 45. [CrossRef]

18. Huebner, C.; Schlaeger, S.; Becker, R.; Scheuermann, A.; Brandelik, A.; Schaedel, W.; Schuhmann, R. Advanced measurement methods in time domain reflectometry for soil moisture determination. In Electromagnetic Aquametry; Kupfer, K., Ed.; Springer: Berlin/Heidelberg, Germany, 2005; pp. 317-347. 
19. Schlaeger, S. A fast TDR-inversion technique for the reconstruction of spatial soil moisture content. Hydrol. Earth Syst. Sci. Discuss. 2005, 9, 481-492. [CrossRef]

20. Scheuermann, A.; Montenegro, H.; Bieberstein, A. Column test apparatus for the inverse estimation of soil hydraulic parameters under defined stress condition. In Unsaturated Soils: Experimental Studies; Schanz, T., Ed.; Springer: Berlin/Heidelberg, Germany, 2005; pp. 33-44.

21. Robinson, D.; Jones, S.B.; Wraith, J.; Or, D.; Friedman, S. A review of advances in dielectric and electrical conductivity measurement in soils using time domain reflectometry. Vadose Zone J. 2003, 2, 444-475. [CrossRef]

22. Kupfer, K.; Trinks, E.; Wagner, N.; Hübner, C. TDR measurements and simulations in high lossy bentonite materials. Meas. Sci. Technol. 2007, 18, 1118. [CrossRef]

23. Siggins, A.; Gunning, J.; Josh, M. A hybrid waveguide cell for the dielectric properties of reservoir rocks. Meas. Sci. Technol. 2011, 22, 025702. [CrossRef]

24. Zhang, J.; Nakhkash, M.; Huang, Y. Electromagnetic imaging of layered building materials. Meas. Sci. Technol. 2001, $12,1147$. [CrossRef]

25. Roth, C.; Malicki, M.; Plagge, R. Empirical evaluation of the relationship between soil dielectric constant and volumetric water content as the basis for calibrating soil moisture measurements by TDR. J. Soil Sci. 1992, 43, 1-13. [CrossRef]

26. Skierucha, W.; Wilczek, A.; Szypłowska, A.; Sławiński, C.; Lamorski, K. A TDR-based soil moisture monitoring system with simultaneous measurement of soil temperature and electrical conductivity. Sensors 2012, 12, 13545-13566. [CrossRef] [PubMed]

27. Kaatze, U.; Hübner, C. Electromagnetic techniques for moisture content determination of materials. Meas. Sci. Technol. 2010, 21, 082001. [CrossRef]

28. Kaatze, U. Reference liquids for the calibration of dielectric sensors and measurement instruments. Meas. Sci. Technol. 2007, 18, 967. [CrossRef]

29. Huisman, J.; Weerts, A.; Heimovaara, T.; Bouten, W. Comparison of travel time analysis and inverse modeling for soil water content determination with time domain reflectometry. Water Resour. Res. 2002, 38, 13-1-13-8. [CrossRef]

30. Topp, G.; Davis, J.; Annan, A.P. Electromagnetic determination of soil water content: Measurements in coaxial transmission lines. Water Resour. Res. 1980, 16, 574-582. [CrossRef]

31. Kelleners, T.; Robinson, D.; Shouse, P.; Ayars, J.; Skaggs, T. Frequency dependence of the complex permittivity and its impact on dielectric sensor calibration in soils. Soil Sci. Soc. Am. J. 2005, 69, 67-76. [CrossRef]

32. Dirksen, C.; Dasberg, S. Improved calibration of time domain reflectometry soil wate-r content measurements. Soil Sci. Soc. Am. J. 1993, 57, 660-667. [CrossRef]

33. Sihvola, A.H. Electromagnetic Mixing Formulas and Applications; IET: Stevenage, UK, 1999.

34. Bore, T.; Schwing, M.; Serna, M.L.; Speer, J.; Scheuermann, A.; Wagner, N. A new broadband dielectric model for simultaneous determination of water saturation and porosity. IEEE Trans. Geosci. Remote Sens. 2018, 56, 4702-4713. [CrossRef]

35. Brovelli, A.; Cassiani, G. Effective permittivity of porous media: A critical analysis of the complex refractive index model. Geophys. Prospect. 2008, 56, 715-727. [CrossRef]

36. Bore, T.; Wagner, N.; Delepine Lesoille, S.; Taillade, F.; Six, G.; Daout, F.; Placko, D. Error analysis of clay-rock water content estimation with broadband high-frequency electromagnetic sensors-Air gap effect. Sensors 2016, 16, 554. [CrossRef]

37. Wagner, N.; Trinks, E.; Kupfer, K. Determination of the spatial TDR-sensor characteristics in strong dispersive subsoil using 3D-FEM frequency domain simulations in combination with microwave dielectric spectroscopy. Meas. Sci. Technol. 2007, 18, 1137. [CrossRef]

38. Leidenberger, P.; Oswald, B.; Roth, K. Efficient reconstruction of dispersive dielectric profiles using time domain reflectometry (TDR). Hydrol. Earth Syst. Sci. Discuss. 2006, 10, 209-232. [CrossRef]

39. Comandini, F.V.; Bore, T.; Six, G.; Sagnard, F.; Lesoille, S.D.; Moreau, G.; Placko, D.; Taillade, F. FDR for non destructive evaluation: Inspection of external post-tensioned ducts and measurement of water content in concrete. In Proceedings of the 10th International Conference on Nondestructive Evaluation (NDE) in relation to Structure Safety for Nuclear and Pressurized Components, Cannes, France, 1-3 October 2013; p. 8.

40. Norgren, M.; He, S. An optimization approach to the frequency-domain inverse problem for a nonuniform LCRG transmission line. IEEE Trans. Microw. Theory Tech. 1996, 44, 1503-1507. [CrossRef]

41. Lundstedt, J.; Ström, S. Simultaneous reconstruction of two parameters from the transient response of a nonuniform LCRG transmission line. J. Electromagn. Waves Appl. 1996, 10, 19-50. [CrossRef]

42. Schlaeger, S. Inversion von TDR-Messungen zur Rekonstruktion räumlich verteilter bodenphysikalischer Parameter; Instituts für Bodenmechanik und Felsmechanik der Technischen Hochschule Fridericiana: Karlsruhe, Germany, 2002.

43. Becker, R.; Schlaeger, S. Spatial time domain reflectometry with rod probes. In Proceedings of the 6th Conference on "Electromagnetic Wave Interaction with Water and Moist Substances", ISEMA, Weimar, Germany, 29 May-1 June 2005.

44. Håkansson, G. Reconstruction of Soil Moisture Profile Using Time-Domain Reflectometer Measurements. Ph.D. Thesis, Royal Institute of Technology, Stockholm, Sweden, 1997.

45. Wagner, N.; Bore, T.; Robinet, J.C.; Coelho, D.; Taillade, F.; Delepine-Lesoille, S. Dielectric relaxation behavior of CallovoOxfordian clay rock: A hydraulic-mechanical-electromagnetic coupling approach. J. Geophys. Res. Solid Earth 2013, 118, 4729-4744. [CrossRef] 
46. Huang, Y. Design, calibration and data interpretation for a one-port large coaxial dielectric measurement cell. Meas. Sci. Technol. 2001, 12, 111. [CrossRef]

47. Hübner, C.; Kupfer, K. Modelling of electromagnetic wave propagation along transmission lines in inhomogeneous media. Meas. Sci. Technol. 2007, 18, 1147. [CrossRef]

48. ASTM D6913-04. Standard test methods for particle-size distribution (gradation) of soils using sieve analysis. Am. Soc. Test. Mater. (ASTM) 2009. [CrossRef]

49. Giroud, J. Development of criteria for geotextile and granular filters. In Prestressed Geosynthetic Reinforced Soil By Compaction, Proceedings of the 9th International Conference on Geosynthetics, Guaruja, Brazil, 23-28 May 2010; IGS Brazil: Sao Paulo, Brazil, 2010; p. 4564.

50. Rassam, D.; Williams, D. A dynamic method for determining the soil water characteristic curve for coarse-grained soils. Geotech Test. J. 2000, 23, 67-71.

51. Chapuis, R.P.; Masse, I.; Madinier, B.; Aubertin, M. A drainage column test for determining unsaturated properties of coarse materials. ASTM Geotech. Test J. 2007, 30, 83-89.

52. Lins, Y.; Schanz, T.; Fredlund, D.G. Modified pressure plate apparatus and column testing device for measuring SWCC of sand. ASTM Geotech. Test J. 2009, 32. [CrossRef]

53. Yan, G. Dynamic Multiphase Flow in Granular Porous Media; Faculty of Engineering, Architecture and Information and Technology (EAIT): Queensland, Australia, 2015.

54. ThermoFisher Scientific. DT80 Range User's Manual; Thermo Fisher Scientific Australia Pty Ltd.: Scoresby, Australia, 2013 ; p. 310.

55. UMS. User Manual of T5/T5x Pressure Transducer Tensiometer; Meter Group AG: Munchen, Germany, 2009.

56. Klute, A.; Gardner, W. Tensiometer response time. Soil Sci. 1962, 93, 204-207. [CrossRef]

57. ASTM D6836-02. Test methods for determination of the soil water characteristic curve for desorption using a hanging column, pressure extractor, chilled mirror hygrometer, and/or centrifuge. Am. Soc. Test. Mater. (ASTM) 2003. [CrossRef]

58. Yang, H.; Rahardjo, H.; Wibawa, B.; Leong, E.-C. A soil column apparatus for laboratory infiltration study. Geotech. Test J. 2004, 27. [CrossRef]

59. Hassanizadeh, S.M.; Gray, W.G. Toward an improved description of the physics of two-phase flow. Adv. Water Resour. 1993, 16, 53-67. [CrossRef]

60. Richards, L.A. Capillary conduction of liquids through porous mediums. J. Appl. Phys. 1931, 1, 318-333. [CrossRef]

61. Kalaydjian, F.-M. Dynamic capillary pressure curve for water/oil displacement in porous media: Theory vs. experiment. In Proceedings of the SPE Annual Technical Conference and Exhibition, Washington, DC, USA, 4-7 October 1992.

62. Yan, G.; Scheuermann, A.; Schlaeger, S.; Bore, T.; Bhuyan, H. Application of Spatial Time Domain Reflectometry for investigating moisture content dynamics in unsaturated sand. In Proceedings of the 11th International Conference on Electromagnetic Wave Interaction with Water and Moist Substances, Florence, Italy, 23-27 May 2016; p. 117.

63. Fredlund, D.G.; Xing, A. Equations for the soil-water characteristic curve. Can. Geotech. J. 1994, 31, 521-532. [CrossRef]

64. Zhou, A.-N.; Sheng, D.; Carter, J. Modelling the effect of initial density on soil-water characteristic curves. Geotechnique 2012, 62, 669-680. [CrossRef] 